\title{
Assessment of Statistical Models for Area, Production and Productivity of Maize Crop in Coimbatore District, India
}

\author{
B. Sivasankari ${ }^{1^{*}}$ and R. Vasanthi ${ }^{2}$ \\ ${ }^{1}$ Agricultural College and Research Institute, TNAU, Madurai, India \\ ${ }^{2}$ Tamil Nadu Agricultural University, Coimbatore, India \\ *Corresponding author
}

\begin{abstract}
A B S T R A C T
The study has been undertaken to fit different trend equations like linear, non-linear and time series models for Maize and also made the future forecasts by 2021 AD. The study was carried out for Coimbatore district of Tamil Nadu state using time series data from 1990 to 2016. For forecasting purpose linear and non-linear growth models viz.,linear, logarithmic, inverse, quadratic, cubic, compound, power, s-curve, growth and exponential and time series models like ARIMA models were fitted to the area, production and productivity of Maize crop in Coimbatore and Coimbatore districts of Tamil Nadu. The best-fitted model for future projection was chosen based upon highest coefficient of determination $\left(\mathrm{R}^{2}\right)$ and significant Adjusted $\mathrm{R}^{2}$ with least RMSE, MAE and MAPE values. The study revealed that cubic model was identified as the best model in Maize area, production and productivity in Coimbatore district of Tamil Nadu ARIMA $(1,1,2)$ model was best fitted in Maize area in Coimbatore district of Tamil Nadu. But regarding production and productivity of Maize area in Coimbatore district, it was found that Cubic model was best fitted. It was also observed that in Coimbatore district of Tamil Nadu, maize showed decreasing trend by $2021 \mathrm{AD}$ in area and production but productivity showed an increasing trend.
\end{abstract}

Keywords

Linear model, Nonlinear model, ARIMA, MAE and RMSE

Article Info

Accepted:

20 September 2020

Available Online:

10 October 2020

\section{Introduction}

Maize is the most important cereal crop cultivated widely throughout the world. It is used as a feed, fodder and it is also used for industrial purposes. In global, USA is the largest producer of maize followed by China and Brazil. In India, maize is cultivated in an area of about 9.26 Mha with the production of 23.67 Mt (Agricultural Statistics, 2014). Andhra Pradesh and Karnataka dominated the production of maize which contributes to around 38 per cent of the total production in India. In Tamil Nadu, maize is cultivated in an area of about 355064 ha with the production of about 2532330 Tonnes (Crop Production Statistics, 2015-16). Tamil Nadu is one of the nine states that accounts for $85 \%$ of India's maize production and $80 \%$ of area under cultivation. In 2016-17 the area, production and productivity of maize in Tamil Nadu are $0.3 \mathrm{~m} \mathrm{ha}, 0.9 \mathrm{~m} \mathrm{t}$ and 3 t/ha respectively. In Tamil Nadu, Perambalur has the highest area of maize about $0.05 \mathrm{~m}$ ha 
which accounts for $15 \%$ of total cultivated area of Tamil Nadu (2015-16). Salem has the highest production of maize about $0.3 \mathrm{~m} \mathrm{t}$. which accounts for $14.9 \%$ of total production of TN. Dindigul and Coimbatore has the highest productivity. To help macro level planning, in this research, it is proposed to fit the most appropriate model for area, production and Productivity of Maize for Coimbatore district of Tamil Nadu. This modeling effort will help on one hand, to understand the past performance and on the other, to forecast future possibility.

\section{Materials and Methods}

The present study was based on secondary data. The time series pertaining to area, production and productivity of maize for Coimbatore district have been collected for the period of 27 years from 1990 to 2016 from the official website Indiastat.com, Seasonal Crop Report. Data was analyzed by using MINITAB and SPSS version 16.0 software. In this study, the linear trend Model was also used by Finger (2007), Broken et al., (2000) and Rimi et al., (2011), Exponential, Quadratic and S-Curve Models of trend analysis were applied for this study. Also Logistic, Monomolecular and fuzzy time series models were fitted for the production data. The best fitted Model was selected on the basis of three accuracy measures. These accuracy measures were Mean Absolute Percentage Error (MAPE), Mean Absolute Deviation (MAD) and Root Mean Square Error (RMSE). Mean Absolute Percentage Error (MAPE) measures the accuracy of fitted time series values. It expresses accuracy as a percentage. Mean Absolute Deviation (MAD) measures the accuracy of fitted time series values. It expresses accuracy in the same units as the data, which helps conceptualize the amount of error. The Root Mean Square Error (RMSE) is a measure of accuracy, to compare forecasting errors of different models for a particular dataset and not between datasets, as it is scale-dependent. Smaller values of all these measures indicate a good fitted Model with minimum forecasting errors (Karim et al., 2010). The relative measures give equal weight to all errors in contrast to the MSE, which squares the errors and there by emphasizes large errors. It would be helpful to have a measure that considers both the disproportionate cost of large errors and provides a relative basis for comparison with naive methods. This statistics allows a relative comparison of normal forecasting methods with naive approaches and also squares the errors involved so that large errors are given much more weight than small errors. The best fitted Model was applied for forecasting area, production and Productivity of Maize in Coimbatore district respectively from the year 2017 to 2021.

\section{Results and Discussion}

In the present study, linear, non-linear models viz., linear, logarithmic, inverse, quadratic, cubic, compound, S-curve, growth, power and exponential models have been fitted where as time series models include Auto Regressive (AR), Moving Average (MA) and Auto Regressive Integrated Moving Average (ARIMA) have been fitted to the data on area, production and productivity of the Maize in Coimbatore district by considering 27 years data from 1990-91 to 2015-16. The results obtained for area of maize in Coimbatore District by fitting all the linear, non-linear and time series models were presented in Table 1.

From Table 1, it was found that all the models fitted well showing significant adjusted $\mathrm{R}^{2}$ values. In comparison with all other models, ARIMA $(1,1,2)$ was with high $\mathrm{R}^{2}(79.1 \%)$ with significant adjusted $\mathrm{R}^{2}(73.5 \%)$ and the low MAPE (23.22) values. Hence, the ARIMA $(1,1,2)$ model was chosen for future forecasts of maize area in Coimbatore district. 
Among the linear, non-linear growth models ARIMA $(1,1,2)$ model was identified as the best fitted model based on model selection criteria.

The results obtained for production of maize in Coimbatore district during the study period by fitting all the models were presented in Table 2.

Forecasted Cubic model is $\widehat{\boldsymbol{Y}}_{\text {production }}=$ $32958.85-10005.02 x+1256.83 x^{2}-34.38$ $\mathrm{x}^{3}$

It appears from Table 2. all the deterministic models showing highly significant adjusted $\mathrm{R}^{2}$ but comparison with model selection criteria among all the models cubic model was with highest $\mathrm{R}^{2}(32 \%)$ with significant adjusted $\mathrm{R}^{2}(23.1 \%)$ has least MAPE (59.37) values. Hence cubic model was chosen for forecasting purpose. Among time series models ARIMA $(1,1,1)$ has the highest $\mathrm{R}^{2}$ and lowest MAPE values. But as compared to cubic model this model is less efficient.

The results obtained for productivity of maize in Coimbatore district during the study period by fitting all the models were presented in Table 3.

Forecasted Cubic model is $\widehat{\boldsymbol{Y}}_{\text {productivity }}=$ $2911.33-850.60 x+82.15 x^{2}-1.74 x^{3}$

It is evident from the Table 3, that the value of $\mathrm{R}^{2}(69.5 \%)$ with significant adjusted $\mathrm{R}^{2}$ $(65.5 \%)$ are higher for cubic model compared to the other linear and non-linear growth models. The value of MAPE (39.25) also lower for cubic model compared to other growth models. Hence cubic model was chosen for forecasting of area, production and productivity of maize in Coimbatore district. Among the time series models ARIMA (1, $1,2)$ was identified as best model based on model selection criteria but as compared to ARIMA $(1,1,2)$ cubic model was best fitted.

Table.1 Linear, non-linear and time series models of Maize area in Coimbatore District of Tamil Nadu

\begin{tabular}{|c|c|c|c|c|c|c|c|c|c|}
\hline \multicolumn{5}{|c|}{ Parameter } & \multicolumn{5}{|c|}{ Criteria } \\
\hline Model & a & b & c & d & $\mathbf{R}^{2}$ & $\operatorname{Adj} R^{2}$ & RMSE & MAE & MAPE \\
\hline Linear & $20666.40^{* *}$ & $-508.74^{* *}$ & & & 33.8 & 31.2 & 5539.96 & 4741.74 & 49.28 \\
\hline Logarithmic & $20430.15^{* *}$ & -2879.97 & & & 12.2 & 8.7 & 6382.80 & 5661.26 & 67.91 \\
\hline Inverse & $13033.34^{* *}$ & 3543.24 & & & 1.1 & 2.9 & 6775.35 & 6030.64 & 79.41 \\
\hline Quadratic & $10975.62^{* *}$ & $1496.25^{* *}$ & -71.60 & & 66.3 & 63.4 & 3956.78 & 3044.56 & 39.37 \\
\hline Cubic & $85765.34^{*}$ & $2439.82^{*}$ & -154.34 & 1.97 & 67.4 & 63.1 & 3889.66 & 3120.94 & 35.89 \\
\hline Power & $27878.56^{* *}$ & $-0.377^{*}$ & & & 22.6 & 19.5 & 7381.54 & 6225.94 & 55.90 \\
\hline $\mathbf{S}$ & $9.23^{* *}$ & 0.69 & & & 4.2 & 0.4 & 7261.08 & 6635.22 & 68.55 \\
\hline Exponential & $25767.82^{* *}$ & $-0.06^{* *}$ & & & 48.9 & 46.8 & 6642.09 & 5201.61 & 40.06 \\
\hline Logistic & $0.000039^{* *}$ & $1.06^{* *}$ & & & 48.9 & 46.8 & 6642.09 & 5201.61 & 40.06 \\
\hline \multicolumn{10}{|c|}{ Time Series Models } \\
\hline \multicolumn{5}{|c|}{ ARIMA $(0,1,0)$} & 75.9 & 69.5 & 3482.80 & 1967.30 & 20.81 \\
\hline \multicolumn{5}{|c|}{ ARIMA $(0,1,1)$} & 74.6 & 65.4 & 3479.90 & 1967.70 & 20.96 \\
\hline \multicolumn{5}{|c|}{$\operatorname{ARIMA}(0,1,2)$} & 76.1 & 70.1 & 3477.00 & 1188.10 & 21.59 \\
\hline \multicolumn{5}{|c|}{$\operatorname{ARIMA}(1,1,0)$} & 75.9 & 66.5 & 3480.10 & 1965.60 & 20.90 \\
\hline \multicolumn{5}{|c|}{$\operatorname{ARIMA}(\mathbf{1}, \mathbf{1 , 1})$} & 76.5 & 71.2 & 3441.60 & 2102.50 & 23.22 \\
\hline \multicolumn{5}{|c|}{ ARIMA(1,1,2) } & 79.1 & 73.5 & 3441.40 & 2103.10 & 23.22 \\
\hline
\end{tabular}

\footnotetext{
**,* indicate significant at $1 \%$ and $5 \%$ level of probability respectively
} 
Table.2 Linear, Non-linear and Time series models of Maize Production in Coimbatore District of Tamil Nadu

\begin{tabular}{|c|c|c|c|c|c|c|c|c|c|}
\hline \multicolumn{5}{|c|}{ Parameter } & \multicolumn{5}{|c|}{ Criteria } \\
\hline Model & $\mathbf{a}$ & b & c & d & $\mathbf{R}^{2}$ & $\begin{array}{c}\text { Adj } \\
\mathbf{R}^{2}\end{array}$ & RMSE & MAE & MAPE \\
\hline Linear & 16424.46 & 1220.97 & & & 8.2 & 4.5 & 31861.82 & 19168.26 & 60.29 \\
\hline Logarithmic & 3261.40 & 12654.25 & & & 9.9 & 6.3 & 31567.19 & 20090.21 & 65.66 \\
\hline Inverse & $39254.61^{* *}$ & -39802.46 & & & 5.6 & 1.8 & 32313.16 & 20563.59 & 68.52 \\
\hline Quadratic & -8920.35 & 6464.72 & -187.28 & & 17.5 & 10.6 & 30204.88 & 20494.15 & 68.13 \\
\hline Cubic & $\mathbf{3 2 9 5 8 . 8 5}$ & -10005.02 & 1256.83 & $-34.38^{*}$ & 32.0 & 23.1 & 27420.47 & 18906.07 & 59.37 \\
\hline Power & $12045.59^{* *}$ & $0.317^{*}$ & & & 17.3 & 13.9 & 32632.23 & 14946.22 & 35.50 \\
\hline $\mathbf{S}$ & $10.307^{* *}$ & -1.066 & & & 11.1 & 7.6 & 33236.24 & 15923.67 & 38.33 \\
\hline Exponential & $16959.37^{* *}$ & 0.030 & & & 13.5 & 10.0 & 33048.94 & 14493.66 & 33.82 \\
\hline Logistic & $0.00005^{* *}$ & $0.971^{* *}$ & & & 13.5 & 10.0 & 33048.94 & 14493.66 & 33.82 \\
\hline \multicolumn{10}{|c|}{ Time Series Models } \\
\hline \multicolumn{5}{|c|}{ ARIMA $(\mathbf{0 , 1 , 0 )}$} & 11.6 & 10.2 & 30680.00 & 13827.00 & 43.31 \\
\hline \multicolumn{5}{|c|}{ ARIMA $(0,1,1)$} & 16.6 & 13.5 & 30199.00 & 14581.00 & 45.92 \\
\hline \multicolumn{5}{|c|}{$\operatorname{ARIMA}(0,1,2)$} & 16.1 & 14.2 & 30093.00 & 15085.00 & 46.09 \\
\hline \multicolumn{5}{|c|}{$\operatorname{ARIMA}(1,1,0)$} & 16.0 & 15.5 & 30180.00 & 14649.00 & 46.46 \\
\hline \multicolumn{5}{|c|}{$\operatorname{ARIMA}(1,1,1)$} & 19.4 & 18.5 & 29888.00 & 15147.00 & 49.28 \\
\hline \multicolumn{5}{|c|}{$\operatorname{ARIMA}(1,1,2)$} & 14.3 & 12.2 & 29740.00 & 15051.00 & 50.30 \\
\hline
\end{tabular}

**,* indicate significant at $1 \%$ and $5 \%$ level of probability respectively

Table.3 Linear, Non-linear and Time series models of Maize Productivity in Coimbatore District of Tamil Nadu

\begin{tabular}{|c|c|c|c|c|c|c|c|c|c|}
\hline \multicolumn{5}{|c|}{ Parameter } & \multicolumn{5}{|c|}{ Criteria } \\
\hline Model & $\mathbf{a}$ & b & c & d & $\mathbf{R}^{2}$ & $\operatorname{Adj} R^{2}$ & RMSE & MAE & MAPE \\
\hline Linear & -449.94 & $239.08^{* *}$ & & & 58.4 & 56.8 & 1606.05 & 1213.45 & 48.43 \\
\hline Logarithmic & -1447.50 & $1817.11^{* *}$ & & & 37.9 & 35.4 & 1855.17 & 1521.24 & 58.13 \\
\hline Inverse & $3542.85^{* *}$ & -4479.34 & & & 13.1 & 9.6 & 2106.62 & 1785.30 & 64.16 \\
\hline Quadratic & 795.89 & -18675.00 & 9.21 & & 62.6 & 59.5 & 1540.49 & 1009.83 & 38.66 \\
\hline Cubic & $2911.33^{*}$ & $-850.60^{*}$ & $82.15^{*}$ & $-1.74^{*}$ & 69.5 & 65.5 & 1441.93 & 974.58 & 39.25 \\
\hline Power & $468.08^{*}$ & $0.63^{* *}$ & & & 43.5 & 41.2 & 1897.43 & 1409.29 & 43.81 \\
\hline $\mathbf{S}$ & $7.87^{* *}$ & $-1.55^{*}$ & & & 15.3 & 11.9 & 2172.44 & 1648.29 & 48.94 \\
\hline Exponential & $666.91^{* *}$ & $0.08^{* *}$ & & & 65.7 & 64.3 & 1658.44 & 1188.03 & 38.55 \\
\hline Logistic & $0.001^{* *}$ & $0.92^{* *}$ & & & 65.7 & 34.3 & 1658.44 & 1188.03 & 38.55 \\
\hline \multicolumn{10}{|c|}{ Time Series Models } \\
\hline \multicolumn{5}{|c|}{ ARIMA $(\mathbf{0 , 1 , 0 )}$} & 45.5 & 43.5 & 1820.60 & 1037.00 & 27.47 \\
\hline \multicolumn{5}{|c|}{$\operatorname{ARIMA}(0,1,2)$} & 60.8 & 58.3 & 1565.10 & 1286.20 & 58.88 \\
\hline \multicolumn{5}{|c|}{$\operatorname{ARIMA}(\mathbf{1}, \mathbf{1 , 1})$} & 54.2 & 50.1 & 1614.30 & 1172.10 & 41.64 \\
\hline \multicolumn{5}{|c|}{$\operatorname{ARIMA}(1,1,2)$} & 61.3 & 60.2 & 1565.00 & 1262.50 & 56.40 \\
\hline
\end{tabular}

**,* indicate significant at $1 \%$ and $5 \%$ level of probability respectively 
Table.4 Forecasted values of Maize Area, Production and Productivity of Coimbatore district

\begin{tabular}{|c|c|c|c|}
\hline Year & $\begin{array}{c}\text { Forecasted Area } \\
\text { (hectares) }\end{array}$ & $\begin{array}{c}\text { Forecasted } \\
\text { Production (tonnes) }\end{array}$ & $\begin{array}{c}\text { Forecasted } \\
\text { Productivity (Kgs/ ha) }\end{array}$ \\
\hline $\mathbf{2 0 1 7}$ & 3007.19 & 15344.06 & 4741.27 \\
\hline $\mathbf{2 0 1 8}$ & 3246.45 & 17444.03 & 6406.90 \\
\hline $\mathbf{2 0 1 9}$ & 2380.62 & 17260.5 & 6631.28 \\
\hline $\mathbf{2 0 2 0}$ & 2513.87 & 17076.96 & 6855.67 \\
\hline $\mathbf{2 0 2 1}$ & 1743.87 & 16893.42 & 7080.06 \\
\hline
\end{tabular}

Forecasting of Maize Area, Production and Productivity using best fitted Model

The future forecasts of area, production and productivity of Maize in Coimbatore district by $2021 \mathrm{AD}$ were calculated and the results were presented in table 4 .

Based on the best identified model (ARIMA model) the area of maize area in Coimbatore district was forecasted and tabulated in the Table 4. The forecasted area of maize area in Coimbatore district by 2021 AD would be 1743.87 hectares. The forecasted values of area showed a decreasing trend by $2021 \mathrm{AD}$ from the average of study period.

Regarding the production of Maize in Coimbatore district Cubic model was selected as the best fitted model for future forecasts by $2021 \mathrm{AD}$ as it had exhibited highest $\mathrm{R}^{2}$ and Adjusted $\mathrm{R}^{2}$ having least MAPE values. From the table 4, by using Cubic model the forecasted production would be 16893.42 tonnes. The forecasted values of Maize production in Coimbatore district showed a decreasing trend by $2021 \mathrm{AD}$ from the average of study period.

Productivity of Maize in Coimbatore district was forecasted by using Cubic model which had exhibited highest $R^{2}$ and Adjusted $R^{2}$ having least MAPE values. By using Cubic model the forecasted productivity would be $7080.06 \mathrm{Kgs} / \mathrm{ha}$. The forecasts showed an increasing trend by $2021 \mathrm{AD}$ from the average of study period and results were presented in the Table 4.

In conclusion the based on the least RMSE, MSE and MAPE value, among all the linear, nonlinear and time series models for Maize area, production and Productivity cubic model was best fitted model for Coimbatore district. It is observed average area, production and productivity of maize in Coimbatore district of Tamil Nadu during the study period were 13544 thousand hectares, 33518 thousand tonnes and $2897 \mathrm{~kg} / \mathrm{ha}$ respectively. The future forecasts of area was worked out by ARIMA (1,1,2) model. The forecasts indicated that there would be considerable decrease in area of Maize. But regarding production and productivity of maize, it was found that Cubic model was best fitted for future forecasts and it revealed that there would be a decreasing trend in production and increasing trend in case of productivity. It was observed that the forecasted area of Maize by 2021 AD would be 1743.87 hectares in Coimbatore district, the forecasted production and productivity would be 16893.42 tonnes and $7080.06 \mathrm{~kg} /$ ha respectively by $2021 \mathrm{AD}$.

\section{References}

Boken VK. Forecasting spring wheat yield using time series analysis: a case study for the Canadian Prairies, Agronomy Journal. 2000; 92(6):1047-1053.

Finger R. Evidence of Slowing Yield GrowthThe example of Swiss Cereal Yield. 
Agri-food and Agri- environmental Economics Group, ETH Zürich, Switzerland. Government of Pakistan. 2012. Economic survey of Pakistan, economic advisory wing, finance department, Islamabad, 2007.

Hassan MF, Islam MA, Imam MF, Sayem SM. Forecasting coarse rice prices in Bangladesh. Progressive Agriculture. 2011; 22(1\&2):193-201.

Karim Md R, Awal Md A, Akter M. Forecasting of wheat production in Bangladesh. Bangladesh Journal of
Agricultural Research. 2010; 35(1):1728.

Rimi RH, Rahman SH, Karmaker S, Hussain G. Trend Analysis of Climate Change and Investigation on its Probable Impacts on Rice Production at Satkhira, Bangladesh, Pakistan Journal of Meteorology. 2011, 6.

Sandika AL, Dushani SN. Growth Performance of Rice Sector: The Present Scenario in Sri Lanka. Tropical Agricultural Research and Extension. 2009; 12(2):71-76.

\section{How to cite this article:}

Sivasankari, B. and Vasanthi, R. 2020. Assessment of Statistical Models for Area, Production and Productivity of Maize Crop in Coimbatore District, India. Int.J.Curr.Microbiol.App.Sci. 9(10): 2686-2691. doi: https://doi.org/10.20546/ijcmas.2020.910.324 